\title{
COMMENTARY
}

\section{A new role for statins in sepsis}

\author{
Jean-Sebastien Rachoin*, Elizabeth Cerceo and R Phillip Dellinger
}

See related research by Patel et al., http://ccforum.com/content/16/6/R231

\begin{abstract}
Several studies have shown promising results regarding the use of statins as an adjunctive treatment for sepsis. Most of those studies were retrospective or observational in nature. The ASEPSIS trial has reported that the administration of atorvastatin reduced clinical progression of sepsis but did not improve mortality. These findings are promising and further multicenter trials are needed to confirm these outcomes and to establish whether this class of medications will offer utility in this regard.
\end{abstract}

\section{Introduction}

In the previous issue of Critical Care, Patel and colleagues report the result of a single-center study that randomized septic patients to atorvastatin or placebo. The authors found that patients treated with statins had less transition to severe sepsis although mortality was no different between the treated and untreated patients [1]. These findings, although promising, need to be confirmed in larger, multicenter trials.

Sepsis is a systemic inflammatory response syndrome triggered by infection, while severe sepsis is organ dysfunction due to infection. Severe sepsis is associated with high rates of morbidity and mortality. The incidence of sepsis has increased over the last few decades and in the United States currently affects more than 750,000 patients annually [1]. Sepsis is estimated to be directly responsible for more than 200,000 deaths and results in $\$ 17$ billion of costs annually [2,3]. An impressive amount of research has been devoted to understanding the pathophysiology of sepsis, and to the testing of potential treatments. Despite significant advances, 30 to $40 \%$ of patients with severe sepsis still die in the ICU [2].

*Correspondence: rachoin-jean@cooperhealth.edu

Department of Medicine, Cooper Medical School of Rowan University, Cooper University Hospital, One Cooper Plaza, Suite 229 Dorrance, Camden, NJ 08103, USA

\section{Main text}

The primaum mauvens in severe sepsis is thought to be an uncontrolled proinflammatory response triggered by infectious agents that leads to organ dysfunction. This response starts when microbial antigenic structures bind to specific receptors on leukocytes and induce a highly complex cascade of biochemical reactions This induction then results in generation of a myriad of proinflammatory and procoagulant agents [4]. In addition to the lipidlowering and cardiovascular protective effects of statins, a significant body of evidence supports their potential role in the amelioration of the proinflammatory process of sepsis. This evidence includes in vitro biologic plausibility studies, animal models, and human trials.

\section{Biologic plausibility}

HMG CoA inhibitors (statins) decrease the production of isoprenoid lipid and inhibit the activation of GTPase protein via their effects on prenylation [5]. Statins have been shown to act on several crucial steps in sepsis: the generation of proinflammatory cytokines (IL-6, IL-8, and TNF $\alpha$ ), modulation of leukocyte and monocyte functions, and reduction of oxidative stress as well as improvement in endothelial function and platelet activity. In one trial, simvastatin reduced the systemic response to endotoxin administration and decreased expression of Toll-like receptors that hold a key early role in sepsis [6]. In addition, an antimicrobial effect of statins on methicillinsensitive Staphylococcus aureus and methicillin-resistant S. aureus has been reported [7].

\section{Animal models}

Animal models on statin use in the setting of sepsis have shown some promising results. In a cecal ligation and puncture mouse model of sepsis, treatment with simvastatin, atorvastatin, and pravastatin but not fluvastatin prolonged survival primarily by improvement of cardiac function and systemic hemodynamics [8].

\section{Human studies}

A significant body of evidence indicates that there may be a role for statins in the treatment of sepsis. Although most of the trials are retrospective and observational in nature, their conclusions are promising. The trial findings 
indicate that statins may decrease the level of inflammatory cytokines, the incidence of de-novo sepsis, the worsening of ongoing sepsis, and possibly also sepsis mortality.

Novack and colleagues randomized 83 patients with acute bacterial infections to simvastatin or placebo and showed that treatment with statins reduced cytokine levels at 72 hours [9].

A retrospective study of 787 patients admitted with pneumonia showed that pretreatment with statins was associated with improved mortality [10].

Some authors have cautioned against the use of statins in the treatment of sepsis due to concerns of myopathy and hepatotoxicity [11]. Prospective randomized controlled trials are therefore needed to definitively establish the appropriate adjunctive role for statins in sepsis and to adequately estimate the magnitude of any possible adverse events.

In the previous issue of Critical Care, Patel and colleagues take a step toward answering the question of whether or not statins are of utility in the prevention of severe sepsis. Within their randomized control setting, the authors minimized biases inherent to retrospective trials. The selection of statin-naïve patients was appropriate but may have hindered some of their potential findings, especially if a prolonged pretreatment period is needed to durably affect outcomes. Showing clinical outcome benefits of statins in a floor population of hospital patients with lower acuity of illness will probably be difficult to demonstrate in the absence of very large trials. The great majority of patients with sepsis do not progress to severe sepsis and therefore prophylactic treatment to prevent severe sepsis would require treatment of a large number of patients who may not benefit. Treatment that shows a decrease in progression to a disease state linked to increased mortality without an effect on decreasing this mortality is also problematic.

\section{Conclusion}

There are some important take-home messages from this study. First, there is a need for larger, multicenter randomized controlled trials in patients with variable degrees of severity of illness, analyzing hard endpoints to establish any role for statins in septic patients. Second, clinicians should probably avoid, if possible, stopping statins in critically ill patients with sepsis who are already taking statins at the time of admission. Given our small armamentarium of agents in sepsis, statins could prove a useful addition.

\section{Abbreviations}

HMG CoA, 3-hydroxy-3-methyl-glutaryl-CoA reductase; IL, interleukin; TNF, tumor necrosis factor.

\section{Competing interests}

The authors declare that they have no competing interests.

Published: 17 January 2013

\section{References}

1. Patel JM, Thickett DR, Linhartova L, Melody T, Hawkey P, Barnett A, Jones A, Hong T, Cooke MW, Perkins GD, Gao F: Randomized double-blind placebocontrolled trial of $40 \mathrm{mg} /$ day of atorvastatin in reducing the severity of sepsis in ward patients (ASEPSIS Trial). Crit Care 2012, 16:R231.

2. Angus DC, Linde-Zwirble WT, Lidicker J, Clermont G, Carcillo J, Pinsky MR: Epidemiology of severe sepsis in the United States: analysis of incidence, outcome, and associated costs of care. Crit Care Med 2001, 29:1303-1310.

3. Melamed A, Sorvillo FJ: The burden of sepsis-associated mortality in the United States from 1999 to 2005: an analysis of multiple-cause-of-death data. Crit Care 2009, 13:R28.

4. Cinel I, Dellinger RP: Advances in pathogenesis and management of sepsis. Curr Opin Infect Dis 2007, 20:345-352.

5. Greenwood J, Steinman L, Zamvil SS: Statin therapy and autoimmune disease: from protein prenylation to immunomodulation. Nat Rev Immunol 2006, 6:358-370.

6. Niessner A, Steiner S, Speidl WS, Pleiner J, Seidinger D, Maurer G, Goronzy JJ, Weyand CM, Kopp CW, Huber K, Wolzt M, Wojta J: Simvastatin suppresses endotoxin-induced upregulation of toll-like receptors 4 and 2 in vivo. Atherosclerosis 2006, 189:408-413.

7. Jerwood S, Cohen J: Unexpected antimicrobial effect of statins. J Antimicrob Chemother 2008, 61:362-364.

8. Merx MW, Liehn EA, Graf J, van de Sandt A, Schaltenbrand M, Schrader J Hanrath P, Weber C: Statin treatment after onset of sepsis in a murine model improves survival. Circulation 2005, 112:117-124.

9. Novack V, Eisinger M, Frenkel A, Terblanche M, Adhikari NK, Douvdevani A, Amichay D, Almog Y: The effects of statin therapy on inflammatory cytokines in patients with bacterial infections: a randomized double-blind placebo controlled clinical trial. Intensive Care Med 2009, 35:1255-1260.

10. Mortensen EM, Restrepo MI, Anzueto A, Pugh J: The effect of prior statin use on 30-day mortality for patients hospitalized with community-acquired pneumonia. Respir Res 2005, 6:82.

11. Vincent A, Miller JA: Statins for sepsis: a cautionary note. Intensive Care Med 2006, 32:795.

doi: $10.1186 /$ cc 11907

Cite this article as: Rachoin JS, et al:: A new role for statins in sepsis. Critical Care 2013, 17:105. 